\title{
ENTREVISTA A LA DOCTORA MARgARITA PALACIOS SIERRA ${ }^{1}$
}

\section{ABRIL USCANGA BARRADAS}

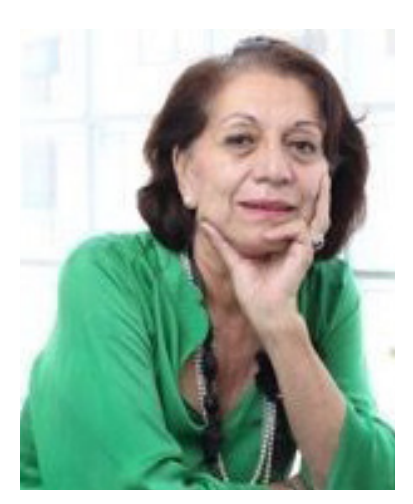

MARGARITA PALACIOS SIERRA obtuvo los grados de licenciatura y maestría en lengua y literaturas hispánicas en la Facultad de Filosofía y Letras de la Universidad Nacional Autónoma de México, hizo estudios de doctorado en la Universidad de Paris en Análisis del Discurso y es doctora en Ciencias Políticas y Sociales con orientación en Comunicación en la Facultad de Ciencias Políticas de la Universidad Nacional Autónoma de México. Fue investigadora del Instituto de Investigaciones Filológicas y ha sido profesora de tiempo completo en la Facultad de Filosofía y Letras desde hace 48 años donde ha recibido la medalla al Mérito Universitario Ha sido asesora del Instituto Nacional de Educación para Adultos, Secretaría de Educación Pública; de la Preparatoria Nacional, del Consejo Nacional de Turismo, del Colegio de Bachilleres y del Colegio de Ciencias y Humanidades. Actualmente es coordinadora del Seminario universitario de Estudios del discurso forense en la UNAM.

1 Este documento constituye una transcripción de la entrevista realizada. Se ha revisado sin alterar el estilo coloquial propio de una conversación, considerando que esta característica enriquecería el texto que se presenta al lector. La entrevista fue realizada con la colaboración de Diana Saldaña Martinez y Javier Cancino Jiménez. 
Entrevista a la Doctora Margarita Palacios

Abril Uscanga Barradas: Muchas gracias por aceptar esta entrevista. Nos gustaría que nos comente un poco acerca de su trayectoria académica y la razón por la que usted decidió estudiar Filología

Margarita Palacios Sierra: Gracias por esta invitación y darme la oportunidad de comentar viejas y vigentes inquietudes. Llegué a la carrera de lengua y literaturas hispánicas porque me gustaba escribir, me gustaba muchísimo escribir, y creí que éste era el camino. Al mismo tiempo, iba a la Facultad de Derecho porque mi padre fue un destacado abogado y él y yo fuimos entrañables amigos. Sin embargo, pronto me di cuenta que tenía más vocación para la lengua y la literatura. Tuve la fortuna de tener un padre abogado, Manuel R. Palacios, que fue generoso e inteligente. Aceptó mi propuesta. A la postre, ninguno de los dos nos equivocamos, mi vocación estaba en la lengua pero su normatividad en el derecho. Hoy vivo a caballo entre las dos disciplinas.

Después, hice un posgrado en la Universidad de Paris donde empecé a meterme en los estudios del discurso. Cursé en México mi maestría en lingüística hispánica porque me di cuenta que para poder manejar y entender el discurso necesitaba dominar las estructuras de la lengua. Fue muy provechoso. Mi maestro fue el distinguido Doctor Juan Lope Blanch. Después decidí hacer mi doctorado, trabajé discurso y finalmente comprendí que para analizar discursos, necesitaba conocer mejor el proceso social, conocer los entornos y saberes donde se desarrollaba esa lengua tan estructurada desde la gramática y que su realización estaba hecha y contra-hecha por los hablantes, así que me fui a la Facultad de Ciencias Políticas de la UNAM a hacer el doctorado en comunicación. Hoy todavía me gustaría estudiar, si tuviera tiempo, derecho, porque creo que finalmente toda la interacción humana se reduce al final a un proceso económico-social normado por el derecho. Mi padre fundó, entre 
otras cosas el Seminario de Derecho Económico y fue emérito de esta Facultad.

AUB: Muy interesante esto que nos comparte Doctora, especialmente porque quiero preguntarle con respecto al fin último de la filología.

MPS: Considero que, nosotros, los que nos hemos dedicado a los estudios filológicos, al estudio de la lengua y sus entornos, hemos sabido siempre que el trabajo filológico implica la reflexión, no sólo sobre la lingǘstica, sino en coincidencia con la literatura, la historia, la filosofía, la jurisprudencia y otras disciplinas como la biología, la informática y la tecnología, más recientemente. El estudio de una disciplina resulta insuficiente. Por ejemplo, un abogado vive, se forma, se forja y trabaja a través de la lengua. Hoy los juicios orales van a obligar necesariamente a habilitar la escucha, a saber hacer el análisis de lo que el otro dice, de lo que pretende decir y de lo que dice cuando no dice. Todo esto está circunscrito a la lengua, no en balde la lengua es lo que nos hace más humanos y nos distingue de los animales. Es una maravilla cuando vemos el cerebro con sus áreas de Broca y Wernicke, y observamos las terminales nerviosas como ramales múltiples por donde pasa toda la motricidad de nuestro cuerpo, y comprobamos que se aloja precisamente en el campo auditivo, para activar las acciones entre Broca en Wernicke. Estas imágenes ponen de manifiesto un proceso cerebral que resulta ser el corazón de la lengua, la capacidad humana de comunicación. En este sentido, la filología siempre ha sido multidisciplinaria. Los filólogos tenemos que ver con la sociedad, con las normas que rigen a esa sociedad, con la psicología, con la medicina, la sociología y muchas disciplinas más. Éste campo es cada vez más multi y trans-disciplinario porque, finalmente, la lengua atraviesa todas las disciplinas del conocimiento.

AUB : ¿Cómo cree doctora que pudiera haber un empate entre la Filología y el Derecho?, es decir, ¿cree usted que pudiera existir un punto en donde el Derecho aporte a la Filología o la Filología hacia el Derecho? 
MPS: Por supuesto, es un puente central. Sabemos bien que somos individuos y sociedad a un tiempo. Este binomio nos ha obligado a regirnos por normas de convivencia y, desde muy pronto, aparecieron diversas formas de gobierno. Una de estas formas fue el sistema teocrático. ¿Qué quiere decir esto? Que han existido normas religiosas y normas jurídicas que nacen de la sociedad y que han terminado regulando la conducta humana. ¿Dónde vemos la conducta humana? En lo que repetimos, en lo que decimos, los refranes, las canciones. Por ejemplo, las tradiciones de una sociedad están plagadas, cargadas de normas, las adelitas de nuestros cantos siguen viviendo, hoy, en nuestras calles, en los espacios cotidianos y no las vemos diferentes, seguimos viéndolas como cuenta la canción, sin reflexionar en la fractura social y humana de estas mujeres, ¿por qué? Porque la norma es pesada, la norma es tradición. La repetición es el principio de la eternidad. La jurisprudencia juega el otro papel normativo. Pensar en una sociedad sin normas es pensar en la selva, en la vida salvaje, en la afirmación del yo sin atender a un tú. Por ejemplo, un niño cuando nace dice "no", ustedes le preguntan, “ppor qué no?” y contesta, "porque no”. Esto es lo más primigenio que existe. Yo he escuchado gente que dice que no va a pagar impuestos "porque no". Se expresan sin reflexionar sobre lo dicho porque en ese caso se tendrían que ir a vivir a un lugar, en soledad, donde no haya reglas, ni normas de conducta y su voluntad sería absoluta. Las normas tienen la fuerza de la colectividad y son determinantes en la vida social de un grupo. Por eso, hasta en nuestras casas, hay normas para limpiar, guardar, convivir. Y todo esto se expresa con palabras.

AUB: De acuerdo Doctora, ahora permítame preguntarle $¿$ Considera usted que han cambiado las generaciones recientes de estudiantes en comparación con las generaciones anteriores, con respecto al uso del lenguaje?

MPS: Yo puedo decirte algo que me da mucho miedo, me da miedo porque tengo la edad en la que puedo ser juzgada como 
vieja retrógrada y el término no me gusta. Y me atrevo, porque me gusta menos claudicar. Considero que a lo largo del tiempo, por condición confortable, hemos perdido o hemos transitado en el entendimiento de ciertos conceptos. Uno de ellos, fundamental en la interacción humana: el respeto. El respeto es exactamente aceptar que el otro existe. Por ejemplo, hoy estamos en un espacio universitario donde ustedes y yo acordamos una tarea universitaria sujeta a ciertas regulaciones, en función de todo esto, estoy sujeta a normas y debo respetarlas. ¿Por qué? Porque hoy todos nos convocamos a una hora y en un lugar y el respeto entre todos nosotros nos exige llegar a esa hora y a ese lugar. Sin embargo, la sociedad en la que vivimos cada vez está más conglomerada, cada vez está más sofocada por seres humanos, congestionada en cuanto a su transporte, vivimos con angustias de seguridad. Esto no sucede solamente en nuestro país, el mundo entero está presionado. Esta presión parece que autorizara al individuo a ignorar los derechos del otro sobreponiendo los propios. Aquí se rompe el principio de respeto a la otredad. Por ello creo que este respeto está fracturado, que paulatinamente nos importa menos lo que le sucede al otro. Hemos desarrollado la capacidad de pasar por una calle sin ver al otro, sin detenernos si tiene problemas. No nos detenemos porque tenemos miedo, porque tenemos prisa, porque no sabemos lo que pueda suceder. Lo más significativo, y esto sí es una barbaridad, es que son acciones normalizadas. ¿Por qué esta regularización de lo arbitrario en defensa o beneficio de la individualidad? Esta regularización del absurdo ha existido siempre en la conducta humana, sin embargo, lo que era excepción, hoy es norma, especialmente entre los jóvenes, quienes asustados ante un porvenir tan inseguro exigen sin ejercer su propia responsabilidad. Creo que en este vértice hay un cambio generacional.

AUB: ¿Cuáles cree usted que puedan ser los cambios más radicales o notorios en el uso del lenguaje en los últimos 10 años, por ejemplo? 
MPS: El uso de términos vacíos, de términos que no indican nada, no detenerme a reflexionar sobre lo que voy a decir, no pensar en el otro que va a recibir mis palabras. En ese momento, aparecen palabras que son campos vacíos, campos que en algún tiempo tuvieron significado pero que lo han perdido y que en algunos casos incluso adquieren formas despectivas, formas de agravio que ya no son agravio, decirle a una persona "que pedo" ya no huele mal, ya no es un agravio, decirle a una persona "oye wey" es mensaje de amistad. Nuestras palabras se han llenado hoy de otros vacíos despectivos que además están autorizados, eso es peligroso. Es tan grave lo que pasa en el lenguaje que después pasa en la manera en la que nos referimos a nuestra inseguridad. Con ese mismo lenguaje preguntamos: “Qué te pasó?” Y contamos la historia del atraco, el robo, el abuso que sufrimos, un hecho que sabemos no tendrá punición, algo que hay que aceptar como parte del acto de vivir. Esta irregularidad aceptada resulta evidente cuando concluimos afirmando: "Bueno, afortunadamente no me pasó nada más, no me mataron, estoy vivo”. ¿Cómo es eso? ¿Está bien que te encañonen? ¿Qué te quiten tu coche? Y luego, ¿damos gracias porque no nos mataron? Estos enunciados están en el discurso cotidiano normalizando hechos de la vida con palabras de significados ambivalentes.

AUB: Doctora como experta en Filología ¿Considera que ha habido un cambio del lenguaje debido al uso de las tecnologías?

MPS: El Doctor Juan Lope Blanch, hace muchos años, publicó un trabajo interesante, un estudio serio, como los que él siempre hizo sobre el habla de la Ciudad de México. Encontró que en el campo del deporte y la tecnología había modificaciones lingüísticas relevantes. Efectivamente, aquella fue una época de auge del deporte, en especial el surgimiento del futbol en los Estados Unidos. Los comentaristas empezaron a importar palabras como corner y outside. Años después comenzó una campaña de reivindicación del futbol mexicano y los términos como tiro de esquina y fuera de lugar marcaron el cambio. ¿Qué quiere decir esto? Que en el momento en que 
aceptamos el futbol mexicano, también adoptamos su lenguaje y lo renombramos con nuestra lengua. Hoy quisiera pensar en algunos pequeños trabajos que hemos estado haciendo con mis grupos de alumnos interesados en estos temas. Hemos verificado que si la computadora llega de los Estados Unidos, que si la tecnología llega del exterior, llega bautizada. Cuando adoptamos un gatito o un perrito, como está de moda hoy, y me parece muy buena moda, éste llega con su nombre, viene de otra casa, ya aprendió a ser llamado así y lo seguimos llamando de esa manera porque de lo contrario no nos va a hacer caso. Lo mismo pasa con la tecnología. Si en México no hacemos ni generamos tecnología, no podemos esperar que estos instrumentos y las acciones que generan tengan nombres en lengua española. Por ejemplo, España empezó a hacer “computadoras-computers" y las llamaron ordenadores, no computadoras. En México no tomamos la palabra de la Península Ibérica, sino del inglés, porque estos aparatos nos llegan desde los Estados Unidos.

AUB: Ahora Doctora, pasado a un tema que a mí me parece muy interesante, especialmente me gustaría comentarlo con usted porque sé que ha realizado algunos trabajos en torno a esto. Se ha considerado por ejemplo que el uso del lenguaje inclusivo es una herramienta que podría favorecer a una sociedad, sin embargo, ha sido rechazado constantemente y no ha habido un consenso claro respecto a cómo debemos integrarlo en nuestras comunicaciones, por lo que quiero preguntarle ¿Es posible modificar los roles sociales a través del lenguaje inclusivo?

MPS: Hay dos teorías, y las dos, yo creo, son válidas. Una dice que la lengua se genera desde el uso hasta la estatificación en la norma, es cierto, es totalmente cierto, lo que se empieza a usar, si se sigue usando durante mucho tiempo, por muchas personas, llega a ser una norma. Esto sucede en el Derecho, ustedes hablan de un Derecho Consuetudinario y este Derecho es ese que se va generando en el uso, en la interacción de la vida humana, y termina siendo una norma. La segunda teoría sostiene que la norma depositada en 
el archivo y por autoritas rige el uso de la lengua. Ambas implican justificaciones. Por ejemplo, a mí me resulta inexplicable la lapidación, sin embargo, en algunos lugares del mundo está permitida. Desde la perspectiva de mi sociedad es inaceptable. Sin embargo, para otras comunidades es una punición autorizada vista desde otro sistema de valores y se normaliza. Es tremendo porque viola derechos humanos que debieran compartirse. Sin embargo, cuando un acto se replica por mucho tiempo y por muchas personas se normaliza y los hablantes usan el término sin sorpresa. Ello nos lleva a normalizar hechos como el robo, los atracos, las violaciones. Cuando esto sucede debiéramos prender focos de alarma social.

En este sentido, cabe señalar que cuando se usan dos o tres palabras para nombrar un mismo hecho se pone de manifiesto que el hecho es un acto inestable y que, en consecuencia no se sabe muy bien como nombrarlo. Esto es interesante porque es un periodo de tránsito, no sólo de la lengua sino del acto social, y también puede suceder al contrario. Existe la posibilidad inversa. Ello consiste en que yo te digo como se dice y tú empiezas a modificar tu concepto. Un ejemplo en este sentido es el término interrupción del embarazo. Con buen tino, los promotores del cambio se dieron cuenta que aborto refería a un hecho censurado por la sociedad, con una fuerte carga semántica religiosa y lo sustituyeron por interrupción del embarazo. Cuando apareció me pareció muy importante, sin embargo, no ha logrado modificar significativamente la percepción de los hablantes ni la valoración social del aborto. Esperemos que con el tiempo se logre.

Como podemos ver la lengua opera en los dos sentidos. Si me preguntas cuál de los dos es más eficiente, te diré que el término que se construye de abajo hacia arriba requiere de más tiempo para consolidarse pero tiene mayor vigencia, por el contrario, el movimiento de arriba para abajo se impone por autoridad pero su aceptación y vigencia son más dudosas. Hay otro ejemplo muy interesante, el de azafata, cuando aparecen estas preciosas señoritas en los aviones, 
la Real Academia de la Lengua decide, desde su autoridad, nombrarlas azafatas. Pero eso no le decía nada al público usuario del término, y las renombraron como aeromozas, con clara referencia a su función de mozas en el aire. Poco después aparecen los mozos, hombres en el aire, los aeromozos, pero el termino mozo tiene una connotación despectiva en la sociedad, el que sirve en niveles inferiores haciendo trabajos manuales, en consecuencia, pronto lo sustituye el termino unisex sobrecargo. ¿Qué quiero decirte con esto? Las formas de femenino y masculino obedecen a una designación social pero, al mismo tiempo, visibilizan un hecho histórico. Hay un libro "Cisnes salvajes", que relata la historia de tres generaciones de mujeres en China, la abuela, la madre y la hija cuyas historias dan anchura al ejercicio de la libertad, a un progreso libertario. ¿Por qué lo llamo progreso? Porque aunque posiblemente algunas abuelas vivían muy felices en su condición de encierro, creo que había otras que no fueron tan felices. En la curva generacional se ganó libertad de acción. Creo que cuando vamos ganando libertad estamos aprendiendo también a usarla. Finalmente, la libertad no es libertinaje, la libertad implica responsabilidad, es brutal tener libertad. Contestar a la pregunta: ¿a dónde vamos a comer?, implica el ejercicio de decidir en libertad. ¿Por qué tengo que hacer uso de mi libertad? Podría ser como mi abuela, ir a donde ellos digan y ellos pagan ¿no? Es cómodo, entonces la libertad es el uso de la responsabilidad y las mujeres concretamente estamos ganando libertad, libertad para quedarnos en la casa y ser como fueron las abuelas o las madres, libertad para ir a trabajar, libertad para tener cinco hijos y casarnos con un señor que quiera mantenernos, libertad para no casarnos, libertad para tener un hijo y no tener una pareja o libertad para tener un hijo con pareja sin habernos casado. Esta es la parte que creo que no se ha comprendido, el lenguaje está sujeto a las normas que la sociedad le imponga. Esta lucha por la libertad se quiere dar desde el lenguaje sin correspondencia con las normas gramaticales. En español las formas plurales no marcan el género femenino distinguiéndolo del 
masculino. El masculino tiene marcas "e", "o", "consonante" y el femenino "a". Estos usos nos llevan a la triste historia de chiquillos y chiquillas, alumnos y alumnas, maestros y maestras, y nos hace caer en absurdos como colegos y colegas. Por eso, aunque creo que el principio es válido desde el movimiento social, desde la lingüística, este uso del lenguaje rompe con las reglas del juego. Es decir, hay una adecuación que es falsa y como la lengua no puede responderla estamos forzando la lengua. La lucha está en el cambio del sistema social, político y económico. La lengua lo reflejará después.

AUB: En ese caso en México esa transición que nos ha venido comentando de forma espectacular, esta expectativa de que el lenguaje en realidad genera cambios culturales y manifiesta los procesos de tradiciones costumbres y normas en una sociedad, no podría darse, por lo que entiendo, sin otros cambios que van de la mano.

MPS: Por supuesto, el gran problema es que necesitamos hacer el cambio en otro lado, el cambio está en el sistema y se expresa en el uso de la lengua. Tenemos que buscar que efectivamente tengamos una equidad, y no hablo solo de una equidad femenina sino de una equidad masculina, y eso si es un trabajo de la ley, ese si es un trabajo del Derecho. A mí me parece terrible que si un hombre quiere quedarse en casa a cuidar a sus hijos no pueda hacerlo y que sea mal visto porque su mujer va a trabajar. Todo sin pensar en la libertad de acción entre las partes. Estos cambios no implican que él deba ser ofendido con palabras como "mandilón” u "holgazán”, ya que él también está cumpliendo una función social. Las tareas están asignadas como dice Bourdieu, en La dominación masculina (1998), para delimitar arbitrariamente las acciones humanas. Se asignan, desde el nacimiento, los colores, los juguetes y los roles a cada uno de los géneros. Yo te diría que en cuestión de género lo que debiéramos tratar de hacer es masculinidades, es decir, formar al sexo masculino con una apertura mayor para propiciar la igualdad femenina. 
AUB: Bueno Doctora, quiero adentrarme a algo que creo que usted es totalmente la adecuada para ayudarme a responder, especialmente ya adentrándonos al discurso que es parte muy importante de esta entrevista ¿Por qué considera usted que es conveniente que el estudiante de Derecho-Que yo sé que usted da clases en el Posgrado- analice el contenido de los discursos?

MPS: Ahí quisiera recapitular un poco. ¿Qué entendemos por discurso? Formo parte de un grupo de discursivistas que generosamente me acoge y mi formación en ese sentido se la debo al Doctor Fernando Castaños. En este marco, el estudio del discurso y se refiere al análisis de los signos, los signos de comunicación humana. El signo lingüístico está inmerso en una situación de discurso ¿Qué quiero decir con situación de discurso? En una situación de interacción comunicativa, para no emplear la palabra discurso. Esa interacción comunicativa es la que nosotros tenemos aquí, está inscrita a su vez en otra mayor que es nuestro espacio universitario que nos rige y ahí hay otra serie de normas que están rigiendo lo que yo estoy hablando y lo que tú me estas preguntando; esto se da prácticamente como si envolvieras una cebolla, capas y capas que se sobreponen y que van construyendo vértices de encuentro que conforman el discurso. Si estudiáramos la palabra aislada, la palabra del diccionario solamente, no podríamos comunicarnos. Cuando queremos entender lo que dice el otro escuchando solamente una palabra y sin reparar en quién se la dijo, a quién se la dijo, en dónde se la dijo, en qué espacio lo dijo, que otros valores interactuaron, de qué mundo viene el que lo dice y a qué mundo pertenece a quién se lo dice, nos quedamos con palabras que no producen sentido en nuestro oyente. Cuando no cuestiono todo esto no puedo entender o estoy entendiendo parcialmente. El discurso es, como explica Wittgenstein la palabra en uso, en un tablero de juego. Me encanta su metáfora del juego de ajedrez, donde tengo libertad para mover las piezas, pero estoy sujeto a las reglas del juego. Eso es el discurso, esas normas de las que me puedo servir, si, con las que puedo jugar 
muchas veces e imaginar pero al mismo tiempo son normas que me constriñen y no son nada más normas gramaticales, esas son las más fáciles, hasta el programa de Word las corrige, son normas de comunicación social no siempre evidentes.

Tengo que ver la palabra en todo el entorno de uso, en ello consiste el estudio del discurso. Sostengo en mi salón de clase que analizar discurso no es hacer "mecae-queísmo", no es "me cae que eso me quiso decir". El estudioso del discurso tiene datos, palabras. Si en tu expresión una palabra antecede a otra, ello indica que me quisiste decir esto y no aquello. Hay un precioso ejemplo de Teun van Dijk, en el que cuenta que en un viaje a Chiapas leyó, en un periódico de la zona, "un tzeltal aprendió español” y se sorprendió del racismo del mensaje porque ello implicaba que nadie se había dado cuenta que muchos tzeltales hablaban español. Lo segundo era una obligación tzeltal, lo primero un acto valioso del policía. Y otro más sencillo, el $1^{\circ}$ de enero de 1994 sucede el levantamiento de los zapatistas y aparece en los periódicos "Ejército Zapatista de Liberación Nacional” (EZLN). Alguien debió haberse dado cuenta del sentido de la frase y el 4 de enero El Universal anuncia: "El autodenominado Ejército Zapatista de Liberación Nacional". El 5 de enero, La fornada contesta "El autodenominado ejército mexicano". En la selección y distribución de estas frases leemos las posturas políticas de los emisores.

AUB: En este mismo sentido Doctora, yo sé que usted dirige un seminario, un Seminario Universitario sobre Estudios de Discurso Forense, con vocación transdisciplinaria, y en el que participan diferentes programas de posgrado, dentro de ellos está Derecho. Considero yo que a veces hace falta un poco de difusión para que los estudiantes sepan que existe este seminario que podría aportar mucho para su formación. Quisiera que nos compartiera un poco acerca de la finalidad del seminario y probablemente también un poco de información para los alumnos que quieran integrarse a estas actividades del seminario, porque entiendo que hay algunas 
posibilidades de elegir materias que son transdisciplinarias, entonces si pudiera hablarnos un poco acerca de esto.

MPS: El Doctor Narro creó el Seminario Universitario de Estudios de Discurso Forense en 2014 para estudiar los conflictos de la sociedad. En mi caso personal le debo a la UNAM, mi vida académica y la felicidad en mi vida cotidiana. Mi trabajo sobre discurso ha sido una constante universitaria. ¿Cómo estudiar estos conflictos de disputa social? La violencia es la explosión visible del conflicto pero se construye en la disputa. La condición económica no explica plenamente el problema. ¿Qué términos la exponen? ¿Cómo se genera? ¿Qué relación se establece entre la norma y la praxis? Ahí empezamos a trabajar, analizando leyes, viendo que decía la ley, viendo que aparecía después en el periódico sobre esa ley, como se aplicaba, tratando de ver qué pasaba en la literatura, como se decantaban estos conflictos. ¿Cómo y dónde se estaban originando desde el discurso, cuáles eran los implícitos de la palabra en estas controversias y disputas sociales? Y así hemos estado trabajando, tenemos hoy corpora etiquetados sobre trata de personas, maltrato infantil, victimas, victimarios, discursos en la Suprema Corte de Justicia, sesiones del Congreso de la Unión sobre la reforma electoral del 2007 y del 2014, sesiones de Alcohólicos Anónimos y entrevistas a padres en duelo. El material se encuentra a disposición del público en la página del seminario: < http://discursoforense.unam. $m x />$ En el Seminario, damos asesoría y propiciamos trabajos de investigación en estos temas. Estamos creando un Posgrado en su modalidad multidisciplinaria, Orientaciones Interdisciplinarias de Posgrado-Estudios Socio-discursivos (OIP-ESD), que será la primera en la UNAM. La OIP ya fue aprobada por los tres comités que la conforman: Derecho (porque establece y regula la vida social), Letras (porque en la literatura se decanta el conflicto) y Ciencias Políticas y Sociales (porque ahí se anida, germina, muere el conflicto). De esta manera hemos conjuntado tres disciplinas centrales. He de resaltar que el trabajo en colaboración ha sido extraordinariamente 
enriquecedor, estamos a punto de tener ya un programa para las materias de discurso que se impartirán, cada alumno puede inscribirse en la maestría o en el doctorado desde su propio posgrado y complementar sus estudios en la OIP-ESD sin tener una carga académica extra, ya que los créditos OIP-ESD se toman en lugar de las materias optativas del posgrado correspondiente. De esta forma, el alumno, al graduarse obtiene el título del posgrado al que pertenece y una constancia complementaria que especifica que ha cursado satisfactoriamente estudios socio discursivos. La idea es precisamente brindar la posibilidad de acercarse al discurso desde todas estas disciplinas y crear gente que pueda moverse dentro de ellas con más facilidad. No quiere decir que el que estudia literatura va a saber derecho pero si quiere decir que va a entender los espacios del derecho y que podrá dialogar con colegas de otras disciplinas para proponer soluciones más pertinentes de manera conjunta. Aunque todavía no está ofertado, empezaremos a trabajar en agosto para iniciar en febrero 2020. Somos una opción muy novedosa, de características multidisciplinarias que satisface nuevas expectativas en los posgrados de la UNAM. Los estudios están integrados a los conflictos sociales e implican todos los beneficios de una transdisciplina. Generan capacidad para comprender mejor y más profundamente los actos sociales.

AUB: Perfecto, Doctora no quiero extenderme más pero si quisiera aprovechar para hacer una última pregunta que dividiré en dos, la primera: tendrá usted alguna recomendación después de ser docente y conocer un poco la formación de los abogados que seguramente habrá carencias con respecto a la filología, y por otra parte, ¿podrá recomendarnos adicionalmente algunos libros, digamos iniciales de Filología que pudieran consultar los alumnos si les interesa el tema, como para iniciarse en temas filológicos?

MPS: Por supuesto, un libro que es muy cautivador, introductorio y accesible, Estructuras y funciones del discurso de Teun van Dijk, está publicado en Siglo XXI, dos acercamientos más didácticos Las cosas 
del decir de Casamiglia y Tusón publicado en Ariel y Decir sin decir de Graciela Fernández publicado por el Colegio de México, un libro más específico, El discurso de la información de Patrick Charaudeau y otro más técnico pero fundamental, La verdad y las formas jurídicas de Foucault ambos publicados en Gedisa, y los trabajos de Fernando Castaños, sobre Shakespeare y Pedro Páramo donde estudia la intención comunicativa y sus entornos a partir de la literatura, que pueden ser consultados en Internet <http://ru.iis.sociales.unam. mx:8080/jspui/handle/IIS/5482>.

AUB: ¿Alguna recomendación en cuanto a la formación de los juristas?

MPS: Bueno, probablemente todos queremos aprender y saber más, a ello obedece que cuando elaboramos planes de estudio siempre intentamos poner más y nunca reflexionamos sobre si lo que estamos proponiendo es central o no para el estudiante. Por eso no quisiera decir que el estudio del discurso se debiera incorporar al plan curricular de su formación. Sin embargo, es muy probable que los estudios del discurso se puedan integrar en alguno de los talleres o en alguno de los cursos que ya se imparten en el curriculum del abogado. Por ejemplo, en la Filosofía del Derecho se debiera hacer referencia a los antecedentes retóricos del discurso y rastrear su camino hasta Wittgenstein. Finalmente, el discurso nace con la Retórica en el mundo griego. En las licenciaturas lo que debemos hacer es instaurar dudas, en la maestría se especializará para encontrar más respuestas y en el doctorado investigará para proponer soluciones. Los programas de estudio son complejos y por ello debieran ser elaborados por grupos de intelectuales y especialistas que generen preguntas básicas ¿Cuáles son esas preguntas básicas? Las que refieren a los conocimientos esenciales en la materia. Formular estos cuestionamientos es un ejercicio educativo central al que todavía no hemos llegado, pero veo que hay gente que está abriendo caminos. En este sentido la herramienta del abogado es la palabra en uso, en el discurso. 
AUB: Doctora, muchas gracias por la entrevista.

MPS: De nada. 